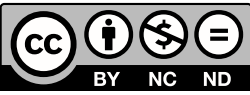

Estudos Teológicos foi licenciado com uma Licença Creative Commons Atribuição - NãoComercial - SemDerivados 3.0 Não Adaptada

http://dx.doi.org/10.22351/etv59i2.3764

\title{
EXEGESE NOS LIMITES DO SENTIDO: OS MÉTODOS HISTÓRICO-CRÍTICOS E AS FORMAS DO MONSTRUOSO ${ }^{1}$
}

\author{
Exegesis at the limits of meaning: \\ historical-critical methods and the forms of the monstrous
}

\section{Elizangela A. Soares ${ }^{2}$ \\ Paulo Augusto de Souza Nogueira ${ }^{3}$}

Resumo: Este artigo discute a narrativa envolvendo os gafanhotos da quinta trombeta no Apocalipse de João (Ap 9.1-12) a partir da teoria estética do monstruoso. Sua intenção é apontar que certos textos, justamente por não poderem ser despidos de seus mitos e/ ou da linguagem mitológica com que foram escritos, apresentam limites aos movimentos demitizantes das interpretações histórico-críticas. Assim, narrativas como as que compõem o Apocalipse de João podem se beneficiar de hermenêuticas menos tradicionais e mais dispostas ao diálogo com suas imagens, símbolos e contradições, uma vez que os monstros de um texto e a forma como eles são articulados podem ser sua chave de leitura.

Palavras-chave: Gafanhotos. Monstro(s). Mito. Demitização. Interpretação.

Abstract: Based on the monster aesthetic theory, this article discusses the narrative involving the fifth trumpet locusts in the Revelation of John (Rev 9.1-12). It intends to point out that certain texts, precisely because they cannot be stripped of their myths and / or the mythological language in which they have been written, present limits to the demitizing movements in historical-critical interpretations. Thus, narratives such as those in Revelation can benefit from less traditional hermeneutics that are more willing to engage with their images, symbols and contradictions, since the monsters found in a text, as well as the way they are articulated in it, can be a key for its reading.

Keywords: Locusts. Monster(s). Myth. Demitization. Interpretation.

1 O artigo foi recebido em 30 de julho de 2019 e aprovado em 27 de agosto de 2019 com base nas avaliações dos pareceristas ad hoc.

2 Mestra. Universidade Metodista de São Paulo, São Bernardo do Campo, SP. E-mail: para.eliz@gmail.com

3 Doutor. Universidade Metodista de São Paulo, São Bernardo do Campo, SP. E-mail: pasn777@outlook.com 


\section{Introdução}

A pergunta sobre a adequação de concepções cosmológicas pré-científicas está no centro do problema da interpretação de elementos míticos no Novo Testamento. Em decorrência, consagrou-se como uma característica pervasiva dos métodos histórico-críticos de interpretação da Bíblia a necessidade de demitizar os textos, fazendo sua interpretação mais palatável para o cristão moderno. Argumentado que a significância de Jesus residia tão somente em seus ensinamentos morais, a solução de protestantes liberais da Alemanha do século XIX para a questão consistiu na eliminação de todos esses elementos nos textos, tornando-os assépticos de todos os vestígios do mito. Com o tempo, porém, essa solução se mostrou insustentável, uma vez que, juntamente com o mito, ela também eliminava dos textos o seu aspecto querigmático.

Rudolf Bultmann, um dos mais influentes teólogos e estudiosos da Bíblia do século XX, levou a demitização ao extremo, fazendo dela o seu procedimento hermenêutico central. ${ }^{4}$ Embora crítico da supressão do querigma pelos liberais, ele acreditava que o ser humano de seu tempo não levaria a sério a concepção de mundo neotestamentária (fortemente embasada no mito), de modo que sua demitização se fazia necessária: "para que a proclamação do Novo Testamento conserve sua validade, não há nada a fazer senão demitizá-lo"s. Para Bultmann, o emprego da linguagem mitológica pela proclamação salvífica era problemático para o pensamento moldado pela ciência. Logo, a crítica à concepção cosmológica neotestamenária seria consequência direta da incompatibilidade entre mito e ciência:

Experiência do mundo e domínio do mundo se desenvolveram tão amplamente na ciência e na tecnologia que nenhuma pessoa pode seriamente sustentar, nem sustenta, a concepção neotestamentária do universo. Qual é o sentido de confessar hoje "desceu ao inferno" ou "subiu ao céu", se aquele que o confessa não compartilha a concepção mítica do universo em três patamares, concepção que se encontra subjacente a essas formulações?

4 Embora a discussão seja mais complexa do que a apresentada aqui, o paradigmático projeto de demitização de Bultmann é digno de menção, pois mesmo que seu autor não seja um consenso, o princípio da demitização é operante. Tendo em vista que a exegese histórico-crítica é muito mais problemática do que cooperativa no que se refere ao mito, o que se pretende é apontar uma caricatura que esses métodos têm em relação a ele, e não fazer um debate completo sobre a questão. Para discussões envolvendo implicações da demitização, cf. RICOEUR, Paul. Preface to Bultmann. In: Essays on Biblical Interpretation. Edited with an introduction by Lewis S. Mudge. Philadelphia: Fortress, 1980. p. 31-46. Ver também LONGENECKER, Bruce W.; PARSONS, Mikeal C. (Ed.). Beyond Bultmann: Reckoning a New Testament Theology. Waco: Baylor University Press, 2014; O'GORMAN, Chester. Demythologizing Revelation: A Critical Continuation of Rudolf Bultmann's Project. Lanham: Rowman; Littlefield Publishing Group, 2019.

5 BULTMANN, Rudolf. New Testament and Mythology - and Other Basic Writings. Philadelphia: Fortress, 1984. p. 9.

6 BULTMANN, Rudolf. Demitologização: coletânea de ensaios. São Leopoldo: Sinodal, 1999. p. 8. Itálicos do autor. 
A demitização proposta por Bultmann não tem a ver, contudo, com uma atualização da cosmologia do Novo Testamento para que ela se conforme a parâmetros científicos modernos. Antes, passa por uma interpretação do que seria a "verdadeira intenção" do mito e dos textos bíblicos, e não por um processo de subtração. ${ }^{7}$

Para entender a "verdadeira intenção do mito", será necessário traduzir os relatos bíblicos em linguagem que revele como a existência humana é "fundamentada e limitada por um poder transcendental e não mundano", mas que não viola nossa cosmovisão científica. $^{8}$

A posição de Bultmann é essencialmente existencialista, tendo pouco ou nada a ver com ciência natural. Uma vez que, para ele, não temos condições de dizer que Deus age no mundo físico sem "objetificá-lo", a tarefa interpretativa é questionar o que o texto está dizendo sobre a existência humana. Dito de outra maneira, trata-se, como ele mesmo classificou, de uma interpretação existencialista das narrativas. ${ }^{9}$

Uma hermenêutica demitizante ou interpretação existencialista não parece, no entanto, apresentar-se como uma ferramenta suficiente ou adequada na abordagem de certas narrativas. Dada a sua dificuldade em lidar com a linguagem do mito (logo, sua tendência à demitização), tal método encontra seus limites diante de composições como, por exemplo, o Apocalipse de João. Marcado por uma imagética simbólica, onírica e grotesca, entrelaçada por uma estrutura labiríntica, impartível do universo mítico, esse texto é um provocativo desafio aos métodos, em especial aos métodos histórico-críticos de leitura das fontes.

De acordo com Paulo Nogueira, “as tradições religiosas recorrentemente se expressam por meio de narrativas e imagens que desafiam radicalmente todo o potencial referencial e comunicacional da linguagem" ". Esse é exatamente o caso com o Apocalipse de João, em que nada parece ser literal, mas forjado diretamente dos sonhos do visionário. Nesse texto, todas as imagens criadas por João são "como", e nenhuma delas é exatamente objetiva. Os relatos do visionário extrapolam as referências da linguagem. É preciso "ver com ele" e abraçar, para desespero de uma hermenêutica demitizante, o universo mítico a partir do qual ele narra. Assim, textos como o Apocalipse de João carecem de ferramentas metodológicas e hermenêuticas que pretendam um passo adiante em relação aos métodos histórico-críticos, ferramentas que trabalhem com o mito e sua linguagem em vez de torná-los dispensáveis ou de reduzi-los, de forma utilitária, a explicações que não possam ser expressas na lingua-

Cf. BULTMANN, 1984, p. 99.

8 REEVES, Josh. Rudolf Bultmann and Demythologization. In: BARTSCH, Hans Werner (ed.). Kerigma and Mith by Rudolf Bultmann and Five Critics. New York: Harper \& Row, 1981. (edição digital, não paginada).

9 Cf. REEVES, 1981. Ver também BULTMANN, 1984, p. 99.

${ }^{10}$ NOGUEIRA, Paulo Augusto de Souza. Modo onírico de narração e de articulação de imagens: hiperconectividade das linguagens da religião. Horizonte, Belo Horizonte, v. 16, n. 51, p. 1008, set./dez. 2018. 
gem objetificadora da ciência. ${ }^{11}$ Com esse argumento no horizonte, este artigo afirma a centralidade do mito para o Apocalipse de João e, em conformidade, seleciona a teoria estética do monstro para discutir o tópico dos gafanhotos na narrativa da quinta trombeta (Ap 9.1-12).

\section{Por que monstros?}

"Há várias coisas que dão origem a monstros.

A primeira é a glória de Deus.

A segunda, sua ira [...]" (Ambroise Paré, Sobre as causas dos monstros).

$\mathrm{O}$ apelo dos monstros parece óbvio: grotescos, eles simultaneamente repelem e fascinam. Quando nos textos, escandalizados ou mesmo horrorizados os leitores não conseguem desviar os olhos do que leem sobre eles, tampouco desimaginar o que imaginam deles. E imaginar o monstro não é difícil, posto que a mente tem um flerte ambíguo, não admitido, insuspeito e inconsciente com o anormal. Não é sem razão que, desde muito tempo, pelo menos no Ocidente europeu, raças monstruosas foram alocadas nos espaços não mapeados do mundo, onde a natureza estaria livre para criar todos os tipos de formas estranhas e mágicas, além dos limites da cultura. ${ }^{12}$

Mas por que falar em monstros? As sentenças iniciais na introdução do belo volume de ensaios de Sorcha Ni Fhlainn sobre o monstro na cultura respondem a essa pergunta com uma obviedade desconcertante:

Vivemos em um mundo habitado por monstros. Nossos monstros tomam a forma humana; residem em nossos sistemas de crenças e em nossos textos culturalmente amados, narram o terreno do nacionalismo e da política, ídolos culturais e representações visuais, cercando-nos com imagens que são frequentemente grotescas, perturbadoras e reveladoras. O que é revelado por meio desses monstros modernos nos leva a um espelhamento do eu humano. Não apenas vivemos em um mundo habitado por monstros - nós mesmos somos monstros. ${ }^{13}$

E o que é, afinal, o monstro? Ainda que fácil de se imaginar, o monstro não é algo igualmente fácil de ser definido. Por exemplo, enquanto autores do mundo clássico e medieval, entre os quais Marcus Cornelius Fronto, Pierre Bersuire e Sir John Mandeville, falam nele como aquilo que é contra naturam ${ }^{14}$, Santo Agostinho

11 Para Bultmann, a linguagem do mito pode funcionar, provisoriamente, para expressar aquilo para o que a linguagem adequada ainda não foi encontrada (BULTMANN, 1984, p. 100).

12 Sobre escritores paradoxógrafos, tais como Ctésias e Megástenes, cuja retórica destacava descrições de povos e maravilhas em outras terras, e cujas narrativas de viagem são divertidas, mas factualmente suspeitas, cf. FRIEDMAN, Block. The Monstrous Races in Medieval Art and Thought. Syracuse: Syracuse University Press, 2000. p. 5ss.

13 FHLAINN, Sorcha Ni (Ed.). Dark Reflections, Monstrous Reflections: Essays on the Monster in Culture. Oxford: Inter-Disciplinary, 2006. p. 11.

14 Cf. FRIEDMAN, 2000, p. 111, 116. 
e Isidoro de Sevilha o veem como parte do plano de Deus, um adorno do universo que também pode ensinar sobre os perigos do pecado. ${ }^{15}$ Mark Dorrian explica que o monstro existe, historicamente, do grego teras ao latim monere e monstrum, "como um sinal a ser interpretado, um símbolo do pecado e do desagrado divino, como o léxico do divino ou do satânico"16. O sentido é o de mostrar, um "efeito de exibição" que emerge da relação com o fenômeno excepcional. Mas o sentido também é o de advertir, de prevenir e de anunciar. Amparado na gama de termos teratológicos oferecida pelo latim (não apenas monstrum, mas também miraculum, omen, ostentum, portentum, prodigium), Orazio Labbate alude à relação ambígua que o ser humano entretém com o monstro, falando dele como um prodígio, um sinal divino diante do qual a pessoa sentirá o horror ou mesmo a atração. ${ }^{17} \mathrm{O}$ monstro tem seu "charme", e isso não se pode negar.

Para Dorrian, a potência do monstro como sinal deriva da opacidade da sua significação. A perda da coerência formal e da unidade, seja por hibridação ou excesso, deficiência ou distorção de membros, incita a interpretação. O monstruoso age, assim como o grotesco (categoria à qual pertence), como um repositório para capturar o que fica entre as classificações da linguagem. A incomensurabilidade interna de figuras monstruosas e grotescas pode ser descrita, mas não é nomeada simplesmente por aquilo que a linguagem concede. Cerca de 50 anos atrás, em "Le prestige du monstre", Jean Brun já apontava dificuldades terminológicas e conceituais do monstro. Para ele, pode-se definir o monstro como um desafio à semântica e uma aventura de sintaxe; todo o seu ser se apresenta como uma rejeição da hermenêutica e como uma errância no labirinto da combinatória morfológica. ${ }^{18}$ Isso reflete os elementos comuns de irregularidade e de estranheza do monstro: qualquer deles representa o resultado da mistura de coisas/objetos/práticas de ordens diferentes; qualquer deles não se integra a categorias como "puro", "fixo" ou "classificável".

Eles são híbridos que perturbam, híbridos cujos corpos externamente incoerentes resistem a tentativas para incluí-los em qualquer estruturação sistemática. E, assim, o monstro é perigoso, uma forma - suspensa entre formas - que ameaça explodir toda e qualquer distinção. ${ }^{19}$

${ }^{15}$ Cf. SANTO AGOSTINHO. A cidade de Deus. 2. ed. Lisboa: Calouste Gulbenkian, 2000. v. II (Livro IX a XV). Livro XV; BARNEY, Stephen A. et al. The Etymologies of Isidore of Seville. Cambridge: Cambridge University Press, 2006. livro XI; VERNER, Lisa. The Epistemology of the Monstrous in the Middle Ages. New York: Routledge, 2005. p. 5-7.

${ }^{16}$ DORRIAN, Mark. On the Monstrous and the Grotesque. Word \& Image: A Journal of Verbal/Visual Enquiry, v. 16, n. 3, p. 312, 2012.

${ }^{17}$ Cf. LABBATE, Orazio. Piccola enciclopedia dei mostri e delle creature fantastiche: Storia illustrata dei 50 mostri che rendono questo mondo un posto spaventoso. Milano: 24 ORE Cultura, 2016.

${ }^{18}$ BRUN, Jean. Le prestige du monstre. Archivio di Filosofia, v. 1, p. 301-322, 1967.

${ }^{19}$ COHEN, Jeffrey Jerome. A cultura dos monstros: sete teses. In: DONALD, James et al. Pedagogia dos monstros: os prazeres e os perigos da confusão de fronteiras. Belo Horizonte: Autêntica, 2010. p. 30. 
Jeffrey Jerome Cohen chama essa perturbadora mistura de "liminaridade ontológica", isto é, sem ser claramente humano nem claramente animal, o monstro é um ser do intervalo, do meio-termo. Ele sempre será definido contra a categoria do normal e da normalidade, com características não relacionadas à ordem natural. É precisamente pelo seu caráter não natural, compósito, formado principalmente de membros e partes heterogêneas, pertencentes a diferentes gêneros e espécies, com aparência deformada e dimensões anormais, que ele induz à admiração e ao medo.

Seu corpo difere do corpo normal na medida em que revela o oculto, algo de disforme, de visceral, de "interior", uma espécie de obscenidade orgânica. Tal obscenidade ele não apenas a exibe, mas também a desdobra, virando a pele pelo avesso e desfraldando-a, sem se preocupar com o olhar do outro, para fasciná-lo. Na realidade, porém, o olhar nada vê, dado que fica suspenso nessa revelação-ocultamento que é a própria imagem do corpo monstruoso [...]. Mostrando o avesso de sua pele, é sua alma abortada que o monstro exibe: seu corpo é o reverso de um corpo com alma. ${ }^{20}$

De tanta mescla, o corpo do monstro transborda; ele é, ao mesmo tempo, "absolutamente transparente e totalmente opaco" ${ }^{21}$. O monstro é, em última análise, sinal e símbolo de uma realidade que não é representável nem exprimível, totalmente fora do curso normal da existência humana. Ele não fala muito de si mesmo. E quanto menos um monstro se explicar, maior a probabilidade de nos envolvermos com ele, procurando pelos nossos próprios significados e explicações. E se isso acontecer, o monstro terá cumprido bem a sua função.

\section{Os gafanhotos monstruosos de Apocalipse 9}

Entre todas as coisas que podem ser contempladas sob a concavidade dos céus, nada é visto que desperte mais o espírito humano, que arrebate mais o sentido, que horrorize mais, que provoque mais terror ou admiração entre as criaturas do que os monstros, prodígios e abominações por meio dos quais vemos as obras da natureza invertidas, mutiladas e truncadas $[\ldots] .^{22}$

A afirmação de Pierre Boaistuau é o lugar de onde partimos para uma introdução aos gafanhotos monstruosos que são apresentados na abertura do quinto selo na narrativa de Apocalipse 9.1-12:

O quinto anjo tocou a trombeta: vi uma estrela precipita-se sobre a terra. Foi-lhe dada a chave do poço do abismo. Ela abriu o poço do abismo, e dali subiu fumaça como de uma grande fornalha. $\mathrm{O}$ sol se escureceu e também o ar. E desta fumaça espalharam-se

${ }^{20}$ PEIXOTO JUNIOR, Carlos Augusto. Sobre corpos e monstros: algumas reflexões contemporâneas a partir da filosofia da diferença. Psicologia em Estudo, v. 15, n. 1, p. 180, jan./mar. 2010.

${ }^{21}$ PEIXOTO JUNIOR, 2010, p. 180.

22 BOAISTUAU, Pierre. Histoires prodigieuses et mémorables: extraictes de plusieurs fameux autheurs grecs, latins, sacrez, profanes, divisées en six livres. Paris: Robert le Mangnier, 1566 (reprod.). 
gafanhotos sobre a terra, e foi-lhes dado um poder semelhante ao dos escorpiões da terra. Foi-lhes dito que não causassem dano à erva da terra, nem a qualquer coisa verdejante, nem a árvore alguma, mas apenas aos homens que não têm o selo de Deus em sua fronte. Foi-lhes dada a permissão, não de matá-los, mas de ser seu tormento durante cinco meses. E o tormento que causam é como o do homem, quando ferido pelo escorpião. Nesses dias, os homens procurarão a morte, mas não a encontrarão; desejarão morrer, e a morte fugirá deles. Os gafanhotos tinham o aspecto de cavalos equipados para o combate; nas suas cabeças havia como que coroas de ouro, e suas faces eram como faces humanas. Tinham cabelos como que de mulheres, e seus dentes eram como dentes de leão. Tinham couraças como que de ferro, e o ruído de suas asas era como o ruído de carros com muitos cavalos, correndo para o combate. Têm caudas como as dos escorpiões, armadas de ferrões; nas caudas reside o seu poder de causar dano aos homens durante cinco meses. Tinham sobre si, como rei, o anjo do abismo, cujo nome em hebraico é Abadon, e em grego Apolion. O primeiro "ai" passou. Dois "ais" vêm ainda, a seguir (TEB).

Rica em detalhes que reforçam certo efeito psicológico, essa é, para todos os efeitos, uma narração de horror. Embora narrativas de horror estejam conosco desde o surgimento das sociedades humanas, sua análise por aquilo que elas podem dizer sobre a cultura da qual emergiram e as inquietações que revelam é algo bastante recente. E no campo dos estudos bíblicos, lançar mão dessa ferramenta de análise de textos é prática de poucos, circunscrita a mais ou menos uma década. ${ }^{23}$

Das bestas do mar e da terra, passando pelo dragão, pela vampira que bebe o sangue dos mártires assentada sobre um monstro e pelos terríveis gafanhotos originados da fumaça do abismo, o Apocalipse de João é, essencialmente, um livro de monstros. Como diz Tina Pippin, “o poder do horror no Apocalipse está encarnado nos seus monstros" "24. Nesse sentido, o livro mesmo é algo como uma obscenidade orgânica (para retomarmos a expressão de Peixoto Junior), um monstro em si, dada a sua desproporção e combinação, multiplicidade na unidade, o muitos em um, tal como um monstro que se preze. O livro, se despido da piedade forçada, da boa nova inexistente e da pretensa esperança, é um monstro que cumpre muito bem a sua função: exibindo

${ }^{23}$ Cf. os trabalhos de NOGUEIRA, Paulo. Narrativa e cultura popular no cristianismo primitivo. São Paulo: Paulus, 2018; KALMANOFSKY, A. Terror All Around: The Rhetoric of Horror in the Book of Jeremiah. New York: T\&T Clark, 2008. (LHBOTS 390); The Dangerous Sisters of Jeremiah and Ezekiel. JBL, v. 130, n. 2, p. 299-312, 2011; Dangerous Sisters of the Hebrew Bible. Minneapolis: Fortress, 2014; Israel's Open Sore in the Book of Jeremiah, JBL, v. 135, n. 2, p. 247-263, 2016; MOBLEY, G. The Return of the Chaos Monsters - and Other Backstories of the Bible. Grand Rapids: Eerdmans, 2012; RAPHAEL, R. Monsters and the Crippled Cosmos: Construction of the Other in Fourth Ezra. In: HARLOW, D. C. et al. (ed.). The “Other” in Second Temple Judaism: Essays in Honor of John J. Collins. Grand Rapids: Cambridge, 2011; KOOSED, J. L. (ed.). The Bible and Posthumanism. Atlanta: SBL, 2014. (SemSt 74); DOAK, B. R. Consider Leviathan: Narratives of Nature and Self in Job. Minneapolis: Fortress, 2014; CASON, T. S. Creature Features: Monstrosity and the Construction of Human Identity in the Testament of Solomon. CBQ, v. 77, n. 2, p. 263-279, 2015; MARZOUK, S. Egypt as a Monster in the Book of Ezekiel. Tübingen: Mohr Siebeck, 2015. (FAT 2; Reihe 76).

${ }^{24}$ PIPPIN, Tina. Apocalyptic Bodies: The Biblical end of the World in Text and Image. London; New York: Routledge, 1999. p. 87. 
o que é anormal à existência humana, sinaliza e simboliza uma realidade que não se pode representar nem expressar.

O Apocalipse de João é uma obra perturbadora, que talvez só pudesse ser, como já se disse certa feita, produto de uma imaginação intensa e psicótica. ${ }^{25} \mathrm{Um}$ argumento nessa linha é oferecido por Timothy Beal, com João apresentado fora de lugar (no exílio, no céu, à beira do mar, no templo), desequilibrado, desconjuntado, às vezes fora do corpo (em espírito). Ele é descrito política, física e psiquicamente sem chão, desalojado, observando, a partir da orla, os horrores que se desenrolam diante dos seus olhos. Para Beal, ao mesmo tempo em que João testemunha a desintegração do mundo, ele também está experimentando a desintegração do seu próprio eu. Sua visão não é apenas uma visão do limite, mas é também uma visão no limite: o limite cósmico, o limite político e o limite físico do visionário. Nessa perspectiva, no Apocalipse de João, a pele do mundo parece se rasgar, abrindo um abismo abaixo da sua superfície que dá à luz monstros inenarráveis. $\mathrm{O}$ texto não vislumbra, assim, o fim do mundo, mas o seu limite. Visto da perspectiva dos espetáculos apocalípticos de João, o mundo é revelado profundamente fora dos eixos, anticonvencional, vacilando no limiar entre nascimento e morte, começo e fim. ${ }^{26}$

A despeito do horror do texto, há quem enxergue nele uma narrativa claramente imperialista, em que a destruição da terra e seus habitantes dá lugar a novos conquistadores, com a predição do desaparecimento do Império Romano equivalendo ao surgimento de um novo império, o cristão. ${ }^{27}$ Christopher Frilingos, defensor dessa tese, apresenta um estudo do Apocalipse relacionando-o intimamente ao seu contexto sociopolítico, lendo-o como uma exploração narrativa das ambiguidades sob o principado romano. Para ele, o autor escreveu uma obra que serve como um espetáculo para a sua audiência, na qual os leitores são convidados a "ver", como espectadores, o show que acontece nas linhas que estão diante dos seus olhos.

Em vez de distanciar o livro do mundo romano, as visões grotescas do Apocalipse surpreendentemente o implicam nas práticas específicas de exibição que haviam "se tornado importantes", para citar Morton Smith, na criação e manutenção da identidade no Império Romano. Roma era uma sociedade do espetáculo, e não é preciso procurar muito para encontrar monstros em exposição no Império Romano. Na arena romana, por exemplo, animais exóticos vindos de todo o império eram exibidos e caçados; e paradoxografias, coleções literárias de "maravilhas", registravam relatos de criaturas fabulosas que viviam nos limites da civilização [...]. ${ }^{28}$

Assim, muito bem integrado ao seu ambiente, na linha de Frilingos o Apocalipse narra espetáculos para a sua audiência a partir de formações discursivas conhecidas do império, haja vista que o monstro representava a grande e última tentação

${ }^{25}$ Cf. ROBINSON, John A. T. Redating the New Testament. Philadelphia: Westminster, 1976. p. 230-231.

${ }^{26}$ BEAL, Timothy K. Religion and Its Monsters. New York; London: Routledge, 2002. p. 72-73.

${ }^{27}$ Cf. FRILINGOS, Christopher A. Spectacles of Empire: Monsters, Martyrs, and the Book of Revelation. Philadelphia: University of Pennsylvania Press, 2004. p. 1.

${ }^{28}$ FRILINGOS, 2004, p. 8. 
para os romanos antigos. ${ }^{29} \mathrm{Ou}$ seja, trata-se de um texto que adota os motivos do espetáculo e da monstruosidade para propósitos cristãos, colocando o Império Romano como "a Besta" que está em guerra contra "o Cordeiro", com santos e pecadores funcionando como os espectadores dessa batalha cósmica. Em suma, o Apocalipse de João, assim como tudo na cultura romana, privilegia o ver. Seu apelo está, pelo menos em parte, no emprego que faz da linguagem, imagética e retórica dos espetáculos que eram familiares para os romanos e formavam um aspecto central na maneira pela qual a identidade era construída naquele mundo. Seus "espectadores textuais" estão persistentemente observando e reagindo aos "shows apocalípticos". Melhor dizendo, eles não apenas contemplam, mas também participam dos quadros horripilantes, de acordo com o princípio da identificação religiosa e em harmonia com o seu contexto social. A imaginação apocalíptica de João é o manancial de uma proliferação de monstruosidades avassaladoras e primordiais que escalam para dentro e para fora do céu, para dentro e para fora do abismo, para dentro e para fora do mundo, ao passo que as fronteiras entre cosmo e caos, céu e inferno, profano e sagrado são removidas na base de muito sangue, violência, taças de pragas e abominações. ${ }^{30}$

Na narrativa sob consideração (Ap 9.1-12), ao soar da quinta trombeta, o visionário vê uma estrela cair do céu, assim como havia sido com o toque da terceira trombeta, cuja consequência foi o envenenamento das correntes e fontes de água (8.10-11). A estrela caída recebeu "a chave do abismo", de onde surge uma invasão de gafanhotos demoníacos. A começar pelas pragas no Êxodo, gafanhotos não são criaturas estranhas às histórias colecionadas na Bíblia, nas quais, pela maior parte, eles funcionam como símbolo de destruição. O exemplo mais vívido nessa linha é encontrado nos dois primeiros capítulos de Joel, cuja descrição de uma invasão de gafanhotos talvez tenha oferecido inspiração ao visionário do Apocalipse. Em Joel, os gafanhotos transformam a vinha em um deserto, destroçam as figueiras, devastam os campos. Por causa deles a colheita está perdida e todas as árvores, secas. Os grãos estão ressecados sob as glebas e os estoques, arrasados. Os animais sofrem com a falta de comida e desfalecem (Jl 1.7-18). Eles são descritos como um povo numeroso e poderoso que escurece o céu; são destrutivos como fogo e nada lhes escapa. Eles são como cavalos e correm como carros, com um barulho que se assemelha à chama que devora o restolho. Eles marcham como gente poderosa, pronta para a batalha. Escalam muralhas, entram nas casas, e diante deles o próprio cosmo se comporta de maneira anormal (Jl 2.1-11).

Ao contrário dos gafanhotos de Joel, aqueles gerados do abismo no Apocalipse de João não são criaturas devoradoras de vegetação. Monstruosos e demoníacos, eles não apenas possuem aspecto terrível e incrível, mas agem contra sua própria natureza: "Foi-lhes dito que não causassem dano à erva da terra, nem a qualquer coisa verdejante, nem a árvore alguma, mas apenas aos homens que não têm o selo de

\footnotetext{
29 BARTON, Carlin A. The Sorrows of Ancient Romans: The Gladiator and the Monster. Princeton: Princeton University Press, 1996. caps. 4 e 5.

${ }^{30}$ BEAL, 2002, p. 79.
} 
Deus em sua fronte" (9.4). O dano que eles infligem aos seres humanos não advém da fome ocasionada pelo alimento devorado ou pelo eventual impedimento do cultivo. Enquanto, no correr normal da existência, gafanhotos atacam plantas, as criaturas da quinta trombeta atacam pessoas! Elas têm o poder dos escorpiões $(9.3,5)$; têm caudas como escorpiões e picadas venenosas (9.10). À diferença das anteriores, o soar da quinta trombeta representa um "ai" dirigido diretamente contra a humanidade, e não contra a natureza.

$\mathrm{Na}$ atualidade, quando a cultura visual já experimentou e experimenta uma imaginação grotesca e monstruosa sem limites, os gafanhotos de João não são tão difíceis de serem visualizados. Eles são cuidadosamente construídos pelo visionário para jogar com a mente: uma mistura, um tudo-em-um animalesco, humanoide e bélico. Sua ferocidade está exposta nos seus dentes (como dentes de leões) e na cauda que ferroa (como cauda dos escorpiões). Entretanto, essa besta alada não é nenhuma das coisas com as quais guarda semelhança. Ela não é compatível com a natureza e com a ordem criada. Ela reúne pedaços de categorias diversificadas, mas não se conforma a nenhuma delas, portanto não se submete facilmente à decodificação. Ela é "como", mais exatamente um conjunto de "comos" articulados grotescamente, parte a parte, fundindo ontologias ${ }^{31}$ que são irreconciliáveis no mundo natural. Os gafanhotos monstruosos da quinta trombeta, nesse sentido, jogam com estratégias de contradição ${ }^{32}$ : eles são não-coisa que ganha existência nos deslocamentos inconscientes, oníricos e involuntários propostos e performados pela mente humana. Nesse aspecto, a provocação de João funciona. A descrição imaginada dos gafanhotos, a imagem construída, seja ela qual for, fica enquadrada e guardada nas profundezas da mente. Dito de outra maneira, uma vez vista, a não-coisa não pode mais ser desvista.

Os híbridos da quinta trombeta não têm permissão para matar as pessoas que não possuem o selo de Deus. Sua função é atormentá-las por um período de cinco meses. E a tormenta, que não é a fome, é a dor: "E o tormento que causam é como o do homem, quando ferido pelo escorpião. [...] têm caudas como as dos escorpiões, armadas de ferrões; nas caudas reside o seu poder de causar danos aos homens durante cinco meses" $(9.5,10)$. E mais: além de físico, o tormento imposto por eles é também psíquico, levando as pessoas à angústia suicida, mas sem conseguir morrer: "Nesses dias, os homens procurarão a morte, mas não a encontrarão; desejarão morrer, mas a morte fugirá deles" (9.6). Os gafanhotos do Apocalipse são um julgamento seguido de uma pena sádica, que é o sofrimento sem alívio. Eles configuram um perigo para o bem-estar tanto do corpo como da mente.

Como o conjunto da obra deixa claro, a experiência do cristianismo descrita no Apocalipse de João é medonha e violenta. E isso vale para pecadores e santos. Todos

${ }^{31}$ Aqui não utilizamos o termo "ontologia" no sentido filosófico, mas segundo o seu emprego nas ciências da computação e sistemas de informação, em que uma ontologia representa um conjunto de conceitos dentro de um mesmo domínio e as relações entre esses conceitos. Nesse modelo de dados, em termos de objetos as ontologias descrevem indivíduos, classes, atributos e relações.

${ }^{32}$ Cf. HARPHAM, Geoffrey Galt. On the Grotesque: Strategies of Contradiction in Art and Literature. Princeton: Princeton University Press, 2006. 
sofrem diretamente, inclusive os que têm o selo de Deus, pois todos habitam o mesmo mundo e partilham das dores da natureza. A diferença é que os que não têm o selo divino sofrem ainda mais. A dor que padecem não tem perspectiva de ser resolvida na morte, já que ela não é opção. Eles não são mártires e nenhuma promessa lhes aguarda. Seu sofrimento, assim como o dos santos, é por causa de Deus, mas em sentido completamente diferente: no caso dos não selados, Deus é a origem da sua agonia!

\section{Deus, um monstro}

"O monstro existe apenas para ser lido" ${ }^{33}$ e, embora não fale muito sobre si mesmo, ele é extremamente eloquente - algo paradoxal, tendo em vista que o monstro, posto que é indescritível, está convencionalmente excluído da linguagem que o determina. Por outro lado, uma vez articulado, isto é, encarnado em palavras, ele não pode mais ser desdito. Então, à vista da eloquência do monstro, como ler os gafanhotos monstruosos do Apocalipse de João? Marie-Hélène Huet afirma que a monstruosidade sempre revela a verdade ${ }^{34}$, e a teoria do monstro que vem se desenvolvendo nas últimas décadas informa que ele, entre outros aspectos, manifesta as ansiedades das sociedades e culturas que o criam. Qual seria, nesse sentido, a ansiedade da narrativa de João? Beal estaria correto em seus arrazoados sobre ele como um visionário no limite? Os monstros que ele cria são descrições desses limites?

Ao introduzir o tema do monstruoso na teia apocalíptica de João, Pippin argumenta que a imagem monstruosa salta aos olhos em cada cena da narrativa. No bestiário que ela identifica no livro, nem mesmo imagens que comumente a interpretação concede como positivas escapam do perfil monstruoso: entre outras, a mulher vestida do sol, a noiva de Cristo, Miguel e seu exército celestial, os 144 mil, o Cordeiro, o Filho do Homem e até Deus. ${ }^{35}$ Assim, se o visionário está em estado de desorientação (como o quer Beal ${ }^{36}$ ), distinguir Deus do monstro, isto é, determinar quem é quem, assim como quem está do lado de quem na batalha, pode se tornar uma tarefa complexa. Nesse ponto, especificamente no que tange à monstruosidade divina, embora não tenha uma forma revelada no texto, Deus não é "uma voz desincorporada no Apocalipse" ${ }^{37}$. Ele está presente o tempo todo como o grande monstro da narrativa. Mesmo que seres sobrenaturais sejam os responsáveis pela execução de uma série de torturas sobre a humanidade, no julgamento final todos eles são superados pelo próprio Criador.

Deus inventa formas mais cruéis de aprisionamento e morte. Uma dor imensa é infligida; a terra no final, durante a "tribulação", torna-se uma câmara de tortura. Schlobin observa corretamente que vemos a destruição "através dos olhos do monstro" (1992:29);

\footnotetext{
33 COHEN, 2010, p. 27.

${ }^{34}$ Cf. HUET, Marie-Hélène. Monstrous Imagination. Cambridge: Harvard University Press, 1993. p. 128.

35 PIPPIN, 1999, p. 88.

${ }^{36}$ Cf. BEAL, 2002, p. 73.

37 PIPPIN, 1999, p. 89.
} 
nós assumimos a posição do monstro quando a vítima é destruída. Existem muitos monstros no Apocalipse, mas o verdadeiro monstro "casca grossa" se senta no trono celestial. $^{38}$

Para Pippin, o holocausto final da humanidade não é perpetrado pelas bestas que representam e encarnam o mal, mas por Deus, pelo Cordeiro e pelo Filho do Homem, os quais são mais ameaçadores, perigosos e letais para a humanidade do que qualquer outro monstro. Aliás, Frilingos fala no Cordeiro descrito "como que morto" como o monstro que se eleva acima dos demais. ${ }^{39}$ "E há muito mais em jogo na promulgação do fim do mundo. O mundo não é salvo, mas destruído e substituído. Deus é um destruidor, o líder do derradeiro massacre." ${ }^{40}$ A mesma ideia está presente em Judith Lee:

[...] em contraste com os apocalipses judaicos intertestamentários, o Apocalipse representa o fim, e não a renovação da criação. De modo mais significativo, enquanto na apocalíptica judaica Deus promete destruição e renovação da terra, o Apocalipse João testemunha diretamente o poder da Palavra divina para descriar o mundo ${ }^{41}$.

Deus, no Apocalipse de João, é imaginado a partir do medo e da dor. Sua presença é revelada no meio da desolação e do horror. Deus é a própria incerteza que Julia Kristeva identifica como o abjeto. ${ }^{42}$ É da sua grande boca que sobem todos os terrores; é pela sua grande boca que tudo é engolido; é pela sua “boca abismal” que os gafanhotos demoníacos escalam para dentro do mundo. Parafraseando Lee, pela sua boca, que ordena a ação do seu anjo, Deus apaga o mundo como texto:

E eu vi: quando [o Cordeiro] abriu o sexto selo, sobreveio um violento terremoto. O sol ficou preto como um pano de crina, e a lua toda como sangue. As estrelas do céu caíram sobre a terra, como frutos verdes de figueira sacudida pela tempestade. O céu recolhe-se como um livro que se enrola, e todas as montanhas e as ilhas foram abaladas (Ap 6.12-14 TEB).

Os gafanhotos compósitos do capítulo 9 são, na linha de Agostinho, parte do plano divino. Eles são um engenho e uma engenhoca de Deus. Totalmente artificiais, a única razão do seu ciclo de vida é executar uma pena atroz. Feito o seu trabalho pelo tempo determinado, desaparecerão. Eles são instrumentos da divindade, criados e guiados por ela. É a vontade divina que eles cumprem: nem mais, nem menos.

38 PIPPIN, 1999, p. 91. Cf. também SCHLOBIN, Roger. Prototypic Horror: The Genre of the Book of Job. Semeia, n. 60, p. 23-38, 1992.

39 FRILINGOS, 2004, p. 6.

40 PIPPIN, 1999, p. 92.

${ }^{41}$ LEE, Judith. Sacred Horror: Faith and Fantasy in the Revelation of John. In: AICHELE, George; PIPPIN, Tina (ed.). The Monstrous and the Unspeakable: The Bible as Fantastic Literature. Sheffield: Sheffield Academic Press, 1997. p. 225.

42 KRISTEVA, Julia. Powers of Horror. New York: Columbia University Press, 1982. p. 15. 
Mas o monstro sempre volta. ${ }^{43} \mathrm{E}$, no caso do monstro por excelência do Apocalipse, Deus mesmo, que não tem qualquer contrapartida no mundo tangível, ele nem mesmo se vai. A humanidade está à sua mais completa mercê, e desse monstro específico ela não pode escapar. De alguma maneira, todos já estiveram ou estarão entre suas unhas e dentes, já ouviram o estalo das suas asas, deram uma boa mirada em sua coroa - inclusive os santos e selados.

\section{Considerações finais}

Um texto como o Apocalipse de João demanda ferramentas de abordagem dispostas a explorar os potenciais de leitura oferecidos pelas construções míticas e por hermenêuticas menos convencionais. Os métodos histórico-críticos, muito comprometidos com processos demitizantes das narrativas, mostram-se limitados para essa tarefa. A separação entre forma e conteúdo, permitida pela teoria de Bultmann, percebe a forma mítica com um veículo equivocado para a transmissão do anúncio (querigma). Na perspectiva de uma semiótica do monstruoso, em que a forma é $o$ conteúdo, isso seria impensável. Os horrores visitam o ser humano em sonhos. Esses sonhos habitam o mundo do mito e falam essa linguagem em sua hiperconectividade. Literalmente "descemos ao inferno" e nosso mundo é habitado por demônios - nunca o mito foi tão atual!

No caso do Apocalipse de João, o pensamento lateral com que o texto joga apresenta ao leitor um conjunto denso, de difícil interpretação, e que não deve ser reduzido a um ou outro dos seus aspectos. O modo pelo qual o visionário do Apocalipse narra e articula suas poderosas imagens é onírico. ${ }^{44}$ Não há aqui preocupações com literalidades, mas um processo que conecta aspectos contraditórios, inclusive a respeito da própria divindade. A linguagem cotidiana não é capaz de encerrar o que ele tenta transmitir - uma dificuldade saliente no texto pelo acúmulo das coisas que são como outras e não coisas em si mesmas. Fica para o leitor o exercício criativo de dar sentido à narrativa, de preencher as lacunas interpretativas deixadas pela falta de linguagem referencial do visionário. Para isso, cabe sonhar e ver monstros junto com João.

\section{Referências}

BARNEY, Stephen A. et al. The Etymologies of Isidore of Seville. Cambridge: Cambridge University Press, 2006. Livro XI.

BARTON, Carlin A. The Sorrows of Ancient Romans: The Gladiator and the Monster. Princeton: Princeton University Press, 1996.

BEAL, Timothy K. Religion and Its Monsters. New York; London: Routledge, 2002.

BÍBLIA. Português. A Bíblia TEB. São Paulo: Paulinas; Loyola, 1995.

${ }^{43}$ Cf. os argumentos na "tese II: O monstro sempre escapa" (COHEN, 2010, p. 27ss).

${ }^{44}$ A esse respeito, ver a íntegra do artigo de NOGUEIRA, 2018. 
BOAISTUAU, Pierre. Histoires prodigieuses et mémorables: extraictes de plusieurs fameux autheurs grecs, latins, sacrez, profanes, divisées en six livres. Paris: Robert le Mangnier, 1566 (Reprod.).

BRUN, Jean. Le prestige du monstre. Archivio di Filosofia, v. 1, p. 301-322, 1967.

BULTMANN, Rudolf. New Testament and Mythology - and Other Basic Writings. Philadelphia: Fortress, 1984.

BULTMANN, Rudolf. Demitologização: coletânea de ensaios. São Leopoldo: Sinodal, 1999.

CASON, T. S. Creature Features: Monstrosity and the Construction of Human Identity in the Testament of Solomon. CBQ, v. 77, n. 2, p. 263-279, 2015.

COHEN, Jeffrey Jerome. A cultura dos monstros: sete teses. In: DONALD, James et al. Pedagogia dos monstros: os prazeres e os perigos da confusão de fronteiras. Belo Horizonte: Autêntica, 2010. DOAK, B. R. Consider Leviathan: Narratives of Nature and Self in Job. Minneapolis: Fortress, 2014.

DORRIAN, Mark. On the Monstrous and the Grotesque. Word \& Image: A Journal of Verbal/ Visual Enquiry, v. 16, n. 3, 2012.

FHLAINN, Sorcha Ni (Ed.). Dark Reflections, Monstrous Reflections: Essays on the Monster in Culture. Oxford: Inter-Disciplinary Press, 2006.

FRIEDMAN, Block. The Monstrous Races in Medieval Art and Thought. Syracuse: Syracuse University Press, 2000.

FRILINGOS, Christopher A. Spectacles of Empire: Monsters, Martyrs, and the Book of Revelation. Philadelphia: University of Pennsylvania Press, 2004.

HARPHAM, Geoffrey Galt. On the Grotesque: Strategies of Contradiction in Art and Literature. Princeton: Princeton University Press, 2006.

HUET, Marie-Hélène. Monstrous Imagination. Cambridge: Harvard University Press, 1993. KALMANOFSKY, A. Dangerous Sisters of the Hebrew Bible. Minneapolis: Fortress, 2014. . Israel's Open Sore in the Book of Jeremiah, JBL, v. 135, n. 2, p. 247-263, 2016. Terror All Around: The Rhetoric of Horror in the Book of Jeremiah. New York: T\&T Clark, 2008. (LHBOTS 390).

The Dangerous Sisters of Jeremiah and Ezekiel. JBL, v. 130, n. 2, p. 299-312, 2011.

KOOSED, J. L. (ed.). The Bible and Posthumanism. Atlanta: SBL, 2014. (SemSt 74).

KRISTEVA, Julia. Powers of Horror. New York: Columbia University Press, 1982.

LABBATE, Orazio. Piccola enciclopedia dei mostri e delle creature fantastiche: Storia illustrata dei 50 mostri che rendono questo mondo un posto spaventoso. Milano: 24 ORE Cultura, 2016. LEE, Judith. Sacred Horror: Faith and Fantasy in the Revelation of John. In: AICHELE, George; PIPPIN, Tina (ed.). The Monstrous and the Unspeakable: The Bible as Fantastic Literature. Sheffield: Sheffield Academic Press, 1997.

LONGENECKER, Bruce W.; PARSONS, Mikeal C. (Ed.). Beyond Bultmann: Reckoning a New Testament Theology. Waco: Baylor University Press, 2014.

MARZOUK, S. Egypt as a Monster in the Book of Ezekiel. Tübingen: Mohr Siebeck, 2015. (FAT 2; Reihe 76).

MOBLEY, G. The Return of the Chaos Monsters - and Other Backstories of the Bible. Grand Rapids: Eerdmans, 2012.

NOGUEIRA, Paulo Augusto de Souza. Modo onírico de narração e de articulação de imagens: hiperconectividade das linguagens da religião. Horizonte, v. 16, n. 51, p. 1008, set./dez. 2018. O'GORMAN, Chester. Demythologizing Revelation: A Critical Continuation of Rudolf Bultmann's Project. Lanham: Rowman; Littlefield Publishing Group, 2019.

PARÉ, Ambroise. On Monsters and Marvels. Chicago; London: The University of Chicago Press, 1982 [1840]. 
PEIXOTO JUNIOR, Carlos Augusto. Sobre corpos e monstros: algumas reflexões contemporâneas a partir da filosofia da diferença. Psicologia em Estudo, v. 15, n. 1, jan./mar. 2010.

PIPPIN, Tina. Apocalyptic Bodies: The Biblical End of the World in Text and Image. London; New York: Routledge, 1999.

RAPHAEL, R. Monsters and the Crippled Cosmos: Construction of the Other in Fourth Ezra. In: HARLOW, D. C. et al. (ed.). The "Other" in Second Temple Judaism: Essays in Honor of John J. Collins. Grand Rapids: Cambridge, 2011.

REEVES, Josh. Rudolf Bultmann and Demythologization. In: BARTSCH, Hans Werner (ed.). Kerigma and Mith by Rudolf Bultmann and Five Critics. New York: Harper \& Row, 1981. (edição digital, não paginada).

RICOEUR, Paul. Preface to Bultmann. In: Essays on Biblical Interpretation. Edited with an introduction by Lewis S. Mudge. Philadelphia: Fortress, 1980.

ROBINSON, John A. T. Redating the New Testament. Philadelphia: Westminster, 1976.

SANTO AGOSTINHO. A cidade de Deus. 2. ed. Lisboa: Calouste Gulbenkian, 2000. v. II (Livro IX a XV). Livro XV.

VERNER, Lisa. The Epistemology of the Monstrous in the Middle Ages. New York: Routledge, 2005. 